Article

\title{
Socio-Spatial Factors Affecting Household Recycling in Townhouses in Pretoria, South Africa
}

\author{
Jacques du Toit ${ }^{1, *}$ (i) , Claire Wagner ${ }^{2}$ and Lizelle Fletcher ${ }^{3}$ \\ 1 Department of Town and Regional Planning, University of Pretoria, Private Bag X20, Hatfield 0028, \\ South Africa \\ 2 Department of Psychology, University of Pretoria, Private Bag X20, Hatfield 0028, South Africa; \\ claire.wagner@up.ac.za \\ 3 Department of Statistics, University of Pretoria, Private Bag X20, Hatfield 0028, South Africa; \\ lizelle.fletcher@up.ac.za \\ * Correspondence: jacques.dutoit@up.ac.za; Tel.: +27-12-420-5765
}

Received: 13 October 2017; Accepted: 31 October 2017; Published: 18 November 2017

\begin{abstract}
Although social factors affecting recycling have been widely researched, the effect of spatial and physical factors posed by medium-density housing, such as townhouses, is less understood. Using the Theory of Planned Behaviour, the relative effect of three sets of factors on household recycling in townhouses are examined, including 'attitude' (about recycling), 'subjective norm' (social pressure), and 'perceived behaviour control' (ability to recycle). A questionnaire survey of 300 households was conducted in Equestria, an enclosed middle-income residential estate consisting of several townhouse complexes. Confirmatory factor analysis verified the three factor measurement model for recycling participation. Both recyclers and non-recyclers showed positive attitudes toward recycling and felt social pressure to recycle. Non-recyclers, however, felt significantly less able to recycle. Most recyclers as well as non-recyclers indicated that certain proposals for increasing recycling may cause them to recycle more, in particular a system through which the management agency arranges access for a recycling company to collect recyclables from strategically located collection points inside the complex. Urban planning and design recommendations for facilitating recycling in townhouses are discussed.
\end{abstract}

Keywords: household recycling; medium-density housing; townhouses; theory of planned behaviour; confirmatory factor analysis

\section{Introduction}

Although recycling has become a norm in many communities [1], South Africa lags behind in this regard [2]. In 2012, only about 10\% of all waste in South Africa was recycled [3], despite the government having identified recycling as a strategic goal towards integrated waste management [4,5]. Legislation also required all major towns and cities to initiate programmes for waste separation at source by 2016, yet, this does not appear to have materialised in most cases. Household recycling is important if this expectation is to be achieved. Still, in 2012, only about 3.3\% of households in South Africa recycled [6]. While South Africa is 'young' in terms of pro-environmental consciousness [7], such a low level of participation requires closer examination of household recycling, especially in medium-density housing such as townhouses. (The South African norm for medium-density is $40-100 \mathrm{du} / \mathrm{ha}$ [8] or $\pm 50-125 \mathrm{du} /$ ha [9].) Townhouse complexes in South Africa are typically located in the suburbs of major towns and cities, and are secured residential developments consisting of medium-sized two- or three-bedroom units in the form of simplexes or duplexes. Most complexes are managed as sectional title schemes. This housing type has grown noticeably in South Africa since political transition due to its affordability, but also due to fear of crime and changing family structures. 
Literature on recycling behaviour focuses largely on psychological factors such as attitudes and social norms [1]. Few studies focus on recycling behaviour in relation to specific housing types. Some of these have examined recycling amongst Asian-British residents in terraced housing [10], recycling in multi-family residential buildings in the UK, US, and Canada [11-13], medium- and high-density housing in the UK [14], high-rise buildings in Hong Kong [15] and single- versus double-storey houses in Malaysia [16]. These studies suggest that less affluent households and households living in higher-density settings recycle less compared to more affluent households and households living in lower-density settings. To our knowledge there are no studies on recycling in townhouses, neither in South Africa nor other developing countries. Yet, townhouses, and townhouse complexes in particular, pose a unique set of spatial and physical challenges to recycling. Kitchens and backyards are generally smaller than what many South Africans are used to, and lack of communal or intermediate spaces for recycling facilities may hamper recycling efforts. Restricted access to security estates deters private recycling companies, and managing agencies and house rules may be unaccommodating of recycling.

Given the unique features of townhouse complexes, the question arises about the relative effect of different social as opposed to spatial and physical factors on household recycling. To what extent are current levels of recycling in townhouses affected by social as opposed to spatial and physical factors, and how may urban planners and architects respond to help facilitate recycling in townhouses? This article examines the relative effect of different socio-spatial factors on household recycling in townhouses in Equestria, an enclosed middle-income residential estate consisting of several townhouse complexes, and tests possible urban planning and design proposals that may increase household recycling.

We first present a theoretical framework for recycling behaviour followed by a discussion of the study method, including the setting in which the study was conducted. We then present results in terms of (1) a socio-demographic profile of respondents and the household recycling rate in Equestria; (2) a confirmatory factor analysis (CFA) to validate core independent factors; (3) the influence of these independent factors on household recycling (determinants of recycling); and (4) preferences for different spatial and physical proposals that may increase household recycling. We discuss recommendations for the planning and design of townhouse complexes, as well as further research into recycling in townhouses.

\section{Theoretical Framework}

Ajzen's [17] Theory of Planned Behaviour (TPB) is a widely used framework for studying environmental behaviour, including recycling [18-21]. According to the TPB, three factors (independent constructs) guide human behaviour (the dependent construct), including 'attitude' towards a certain behaviour (i.e., beliefs about the consequences of performing the behaviour), 'subjective norm' (i.e., perception of others' expectations of one to perform the behaviour, notably social pressure), and 'perceived behavioural control' (PBC) (i.e., how much control one believes one has to perform the behaviour, notably the ability to perform the behaviour). The interaction between these three factors leads to an intention to perform a certain behaviour, and eventually the behaviour itself. In its simplest form, the TPB suggests that if people's attitude towards a certain behaviour is positive, there is enough social pressure, and they believe they are able to perform the behaviour, then their intention to perform that behaviour-in this case recycling, should be strong [22].

Although Tonglet et al. [18] and $\mathrm{Xu}$ et al. [21] suggest the inclusion of additional independent constructs, such as moral norm, past experience and perceived consequences of recycling, we found the original framework of the TPB sufficient to address our main question about the relative effects of social as opposed to spatial and physical factors. Thus, the core constructs of 'attitude', 'social norm', and 'PBC' allowed sufficient differentiation between the effects of social as opposed to spatial and physical factors, provided we were able to adopt a wider conceptualisation of PBC to include situational factors such as storage space and access to recycling facilities [23]. This study, arguably being the first to examine the applicability of the TPB in examining recycling behaviour in townhouses, 
therefore, provides a basis for further studies that may include additional independent constructs or compare recycling behaviour in townhouses with other forms of housing.

Considering the focus on spatial and physical factors in this study, important findings from the literature around the construct of PBC are briefly summarised. People will not recycle if they perceive it as inconvenient, even though they may have a positive attitude towards recycling $[18,24,25]$. In fact, if access to recycling infrastructure is convenient, attitudes toward recycling impact less on actual behaviour $[26,27]$. Kerbside recycling collection has shown the most significant influence on behaviour [28,29], although it may require access to additional bins [30] and ample storage space [26]. Yard size can also determine the preference for different modes of recycling, with smaller properties being more amenable to bags as opposed to a wheelie bin [10]. The importance of measuring the perceived ability to recycle in settings where facilities are lacking or where there are spatial and physical constraints, such as in the present study, is evident $[10,24,25,31]$.

\section{Method}

\subsection{Measurement and Questionnaire Design}

Using the TPB framework, we designed a questionnaire to capture basic socio-demographic characteristics of households, including their actual recycling behaviour. We formulated items to measure the TPB constructs considering the literature cited above as well as the socio-spatial context of townhouse complexes in South Africa. Table 1 shows the items that were used to measure the constructs of 'attitude' (towards recycling), 'subjective norm' (social pressure), and PBC (ability to recycle).

Table 1. Questionnaire items used to measure TPB constructs.

\begin{tabular}{|c|c|c|}
\hline $\begin{array}{c}\text { 'Attitude' } \\
\text { (about Recycling) }\end{array}$ & $\begin{array}{l}\text { 'Subjective Norm' } \\
\text { (Social Pressure) }\end{array}$ & $\begin{array}{c}\text { 'Perceived Behavioural Control' } \\
\text { (Ability to Recycle) }\end{array}$ \\
\hline $\begin{array}{l}\text { "Please indicate the extent to which } \\
\text { you agree or disagree with the } \\
\text { following statements:" }\end{array}$ & $\begin{array}{l}\text { "Please indicate the extent to which } \\
\text { you agree or disagree with the } \\
\text { following statements:" }\end{array}$ & $\begin{array}{l}\text { "On a scale of } 1 \text { to } 5 \text {, with ' } 1 \text { ' being 'not at } \\
\text { all', and ' } 5 \text { ' being 'to a large extent', to what } \\
\text { extent..." }\end{array}$ \\
\hline $\begin{array}{l}\text { Recycling is important for the sake of } \\
\text { the environment. (A1) } \\
\text { Recycling is not worth the cost } \\
\text { incurred by recycling companies. (A2) } \\
\text { Recycling is important to help reduce } \\
\text { waste in municipal landfills. (A3) } \\
\text { Recycling is not worth the effort } \\
\text { incurred by households. (A4) }\end{array}$ & $\begin{array}{l}\text { My family and friends would like me } \\
\text { to recycle my household waste. (SN1) } \\
\text { My neighbours would approve of me } \\
\text { recycling my household waste. (SN2) } \\
\text { My local authority (City of Tshwane) } \\
\text { expects me to recycle my household } \\
\text { waste. (SN3) }\end{array}$ & $\begin{array}{l}\ldots \text { do you have information on what, where, } \\
\text { when and how to recycle? (PBC1) } \\
\ldots \text { is there sufficient space or facilities } \\
\text { within your house to do recycling? (PBC2) } \\
\ldots \text { is there sufficient space or facilities in } \\
\text { your yard to do recycling? (PBC3) } \\
\ldots \text { is there sufficient space or facilities inside } \\
\text { your estate to do recycling? (PBC4) } \\
\ldots \text { does your body corporate or resident } \\
\text { association promote or support recycling } \\
\text { inside your estate? (PBC5) } \\
\ldots \text { do recycling companies have access to } \\
\text { your estate to collect recyclables? (PBC6) } \\
\ldots \text {. do you have access to a kerbside or } \\
\text { collection point for recycling just outside } \\
\text { your estate? (PBC7) }\end{array}$ \\
\hline
\end{tabular}

'Attitude' and 'subjective norm' were measured with four and three normative statements respectively about recycling followed by five-point Likert scales ranging from 'agree completely', 'agree', 'neither agree nor disagree', 'disagree', to 'disagree completely' (e.g., see Martin et al. [10]). The small number of indicators for 'subjective norm' was still sufficient for a CFA. Kline [32] indicates that at least three indicators are necessary to meet the identification criterion for a standard CFA with a single factor, while at least two indicators per factor are required for a model with two or more factors. 'PBC' was measured with seven questions about the household's ability to recycle followed by five-point Likert scales ranging from 'not at all' towards 'to a large extent'. We followed a similar approach to Tonglet et al. [18] by using a combination of traditional PBC items (ease and 
opportunity) and facilitating/inhibiting items (knowledge and resources). Davies et al. [23] argue that facilitating/inhibiting items provide a more valid measure of PBC than traditional items and are more appropriate for settings lacking recycling facilities.

Even though our conceptualisation of 'attitude' conforms to Wan et al.'s [33] conception of an experiential and instrumental dimension to attitude, we did not include a cognitive dimension (i.e., knowledge of the consequences of recycling) as identified by Davies et al. [23]. Another possible shortcoming, is that we operationalized social norms in terms of injunctive norms only, i.e., the perceived expectation by others that one should recycle, without any descriptive norms, i.e., the knowledge that others recycle [1]. We assumed, however, that due to the lack of formal recycling facilities in Equestria at the time of the study, respondents would have had little knowledge of whether their neighbours actually recycled or not. As a compromise, we specified our measure of social norms by relating each item to a specific social group instead of the unspecified phrase ' ... most people who are important to me ... ' used in certain studies (e.g., see Tonglet et al. [18]). We also did not ask whether respondents thought they had enough material to recycle, assuming that middle-income households probably would have enough.

Considering that the construct of 'intention' in the TPB has been criticised for failing to predict actual behaviour, especially recycling behaviour in settings lacking adequate facilities [23], we did not measure intentions to recycle as per the original TPB framework. Instead, we captured actual household recycling with a question that asked respondents whether their households had recycled any paper, glass, metal or plastic (i.e., dry recyclables) in the past three months followed by a binary 'yes/no' response. As we were also interested in urban planning and design solutions, we measured the intention to recycle with five-point Likert scales that asked respondents about the extent to which four different spatial and physical proposals may cause their households to recycle more or not. The questionnaire concluded with a single open-ended question that asked respondents to share any further thoughts they may have had about recycling in enclosed residential developments. Following translation of the questionnaire to include an Afrikaans version, we piloted the questionnaire and submitted the final version for ethical clearance. Clearance was granted on the 19th of May 2014 by the Research Ethics Committee of the Faculty of Engineering, Built Environment, and Information Technology at the University of Pretoria (reference number EBIT/16/2017). The clearance required all respondents to agree to an informed consent statement that indicated that participation was completely voluntary and that all responses would be treated anonymously.

\subsection{Research Setting}

We conducted this study in Equestria, an enclosed middle-income residential estate of about 1250 units on the eastern edge of Pretoria, the administrative capital of South Africa. Equestria consists of 13 sub-estates, most of which are townhouse complexes each with their own enclosure and controlled access. Sub-estates in Equestria are therefore double-enclosed. The townhouse complexes are typically of medium-density with either single- or double-storey units averaging around 90 square meters. Figure 1 shows the layout plan of Equestria.

Like most privatised residential estates in South Africa, Equestria has a closed road network with limited access points. Given a profit-driven housing market, space is only allocated for driveways, visitor parking, and residential units. As with many similar estates in South Africa, there is little communal or intermediate space between units that could have contained recycling facilities. The obstacles for recycling, both in terms of lack of communal space for household participation and access for recycling companies, is clear. 


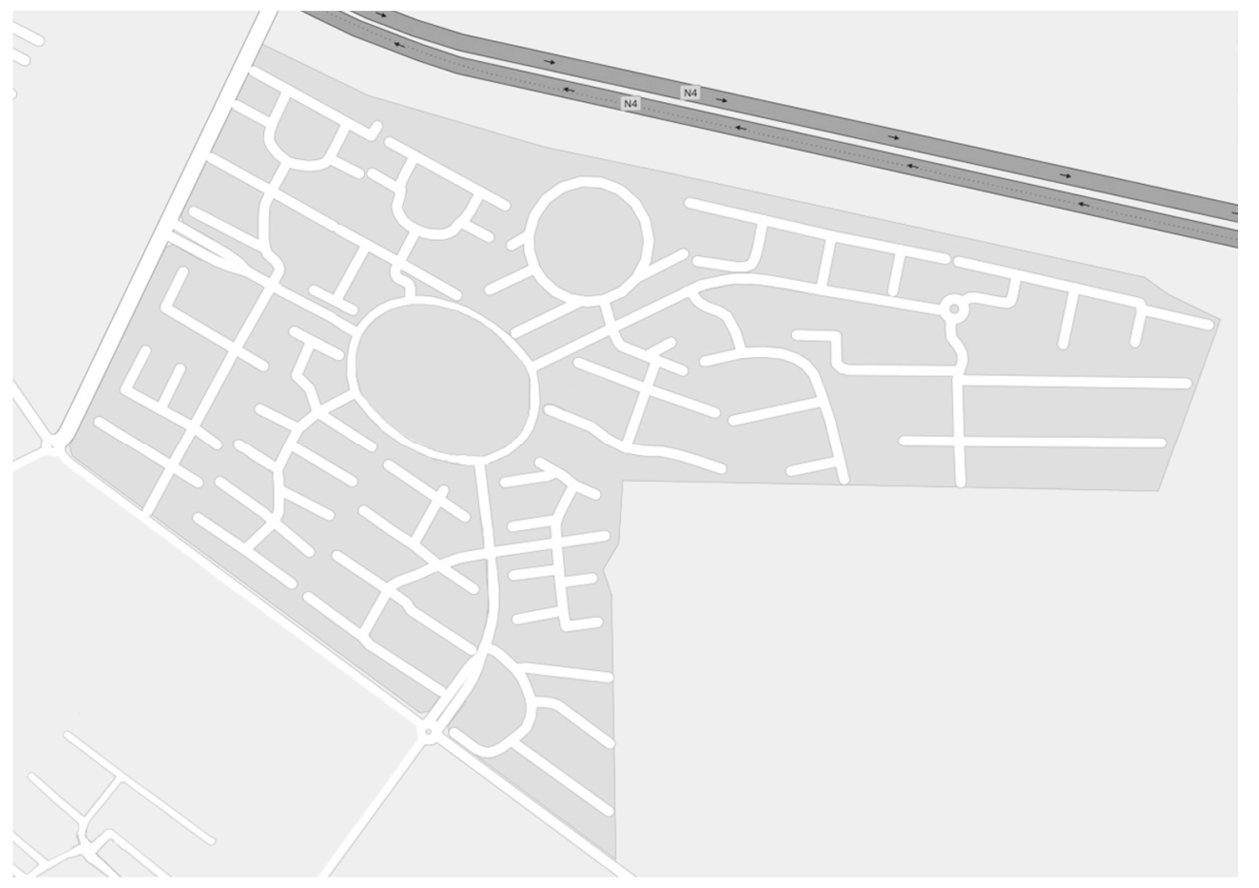

Figure 1. Layout plan of Equestria.

\subsection{Data Collection}

We conducted a household survey in Equestria using self-administered questionnaires that measured household recycling behaviour as outlined in Section 2. After Equestria's management agency granted permission for the survey, seven students, who participated in the study as part of their final year research project, negotiated access to five purposefully sampled sub-estates within Equestria. These five sub-estates were more typical of townhouse complexes in South Africa compared to the other sub-estates. The students surveyed 300 units proportionally across the five sub-estates using lists of unit numbers and simple random sampling. Considering that we obtained ethical clearance to survey residents of 19 years or older (i.e., residents past the school-going age in South Africa), the students identified a household member of 19 years or older in each sampled unit who was the most appropriate person to answer the questionnaire. The students introduced the study, obtained informed consent, and then asked respondents to complete the questionnaire in their presence. The students could therefore assist respondents with clarifying questions and encourage non-recycling households to participate if they thought the study applied to recyclers only.

Upon completion of the survey, random spot-checks were conducted on a small sample of completed questionnaires collected by each student. After authenticating each student's batch of questionnaires, data were captured, cleaned, and analysed using EQS 6.1 (Multivariate Software, Inc., Temple City, CA.) for the CFAs and SPSS 22 (International Business Machines Corp., Armonk, NY, USA) for the descriptive statistics. Since some of the Likert scales were reversed, we were able to identify a response set in two cases. These two cases were removed to yield a final sample of 298 valid responses.

\subsection{Data Analysis}

We first conducted a CFA to determine construct validity, i.e., convergent and discriminant validity, for the three TPB constructs of 'attitude', 'subjective norm', and 'perceived behavioural control' using software that allows for the explicit specification of categorical variables. Since the items were measured on a five-point Likert scale, making them categorical in nature, the assumption of normality, which is needed for the conventional maximum likelihood method when estimating parameters in a 
CFA, is violated. We therefore used polychoric correlations to obtain parameter estimates together with robust fit indices (e.g., see Byrne [34]). To evaluate the model fit, we used the Satorra-Bentler (S-B) scaled chi-square, the Bentler-Bonnett normed and non-normed fit index (NFI, NNFI), the conventional comparative fit index (CFI), Bollen's incremental fit index (IFI), and the root mean-square error of approximation (RMSEA). As a measure of overall fit, we also calculated the more reliable ratio between the chi-square and the degrees of freedom (df), instead of relying on the significance of the chi-square statistic due to its sensitivity to large sample sizes [35]. A step-by-step model refinement process was followed using the modification indices based on the Lagrange multiplier test to conceptually validate the adjustments (e.g., see Chou and Bentler [36]).

After having determined construct validity, we calculated the composite score for each TPB construct and conducted two-independent samples t-tests to determine differences between recyclers and non-recyclers with regard to these constructs, as well as differences in their preferences for various proposals to increase household recycling.

\section{Results}

\subsection{Socio-Demographic Profile of Respondents and Household Recycling Rate}

Table 2 shows the socio-demographic profile of respondents in terms of gender, age, highest level of education completed, and position in the household.

Table 2. Socio-demographic profile of respondents.

\begin{tabular}{|c|c|c|c|}
\hline & Socio-Demographics & Frequency, n & Percent, $\%$ \\
\hline \multirow{3}{*}{ Gender } & Female & 182 & 61.1 \\
\hline & Male & 116 & 38.9 \\
\hline & Total & 298 & 100.0 \\
\hline \multirow{4}{*}{ Age } & 19-35 Years & 201 & 67.4 \\
\hline & 36-59 Years & 91 & 30.5 \\
\hline & $60+$ Years & 6 & 2.0 \\
\hline & Total & 298 & 100.0 \\
\hline \multirow{5}{*}{$\begin{array}{l}\text { Highest level of } \\
\text { education completed }\end{array}$} & Matric/Grade 12 or less & 62 & 20.8 \\
\hline & Certificate or diploma & 92 & 30.9 \\
\hline & Bachelor or honours & 121 & 40.6 \\
\hline & Masters or doctoral & 23 & 7.7 \\
\hline & Total & 298 & 100.0 \\
\hline \multirow{4}{*}{$\begin{array}{l}\text { Position in the } \\
\text { household }\end{array}$} & Head of the household & 156 & 54.0 \\
\hline & Spouse of the head of the household & 90 & 31.1 \\
\hline & Other (e.g., dependent) or not applicable (e.g., cohabiting) & 43 & 14.9 \\
\hline & Total & $289^{1}$ & 100.0 \\
\hline
\end{tabular}

${ }^{1}$ Nine respondents did not indicate their position in the household.

At the time of the study, household members in Equestria mainly responsible for the recycling of dry materials were predominantly female, 19 to 35 years old, qualified at a tertiary level, and/or head of the household. The average household size was around three persons. There was no formal recycling system in place at Equestria at the time of the study, while some residents alleged that previous attempts failed due to poor organisation and lack of participation. Respondents who indicated that their households had recycled in the past three months would therefore have had to make use of facilities outside the estate, such as drop-off facilities at nearby schools, offices, or shopping centres. Consequently, only about $31 \%$ of respondents reported that their households had recycled paper, glass, metal, or plastic in the past three months-a rate that is equal to the national average for the UK [14], and marginally higher than the rate in multi-residential buildings in Ontario (Canada) [13]. However, considering social desirability bias and the tendency for self-reported recycling to be overstated, the actual rate of recycling in Equestria is likely to be lower [1,13,14,37,38]. 


\subsection{Confirmatory Factor Analsyis}

The initial three-factor CFA model that we constructed to determine construct validity for 'attitude', 'subjective norm', and 'perceived behavioural control', did not sufficiently fit the data $(\mathrm{S}-\mathrm{B}$ chi-square $(74 \mathrm{df})=251.315$; chi-square ratio $=3.396 ; \mathrm{NFI}=0.714 ; \mathrm{NNFI}=0.723 ; \mathrm{CFI}=0.775$; $\mathrm{IFI}=0.780$; RMSEA $=0.107$ ). Large covariance errors contributed substantially to this misfit, specifically between the two items 'Recycling is not worth the cost incurred by recycling companies' and 'Recycling is not worth the effort incurred by households', the two items ' ... is there sufficient space or facilities in your yard to do recycling?' and '. . . is there sufficient space or facilities inside your estate to do recycling?', as well as the two items ' ... does your body corporate or resident association promote or support recycling inside your estate?' and '. . . do recycling companies have access to your estate to collect recyclables?'. Figure 2 shows standardized values of path coefficients and covariances among the observed and latent variables of the final three-factor CFA model after adding the above-mentioned covariances to the model.

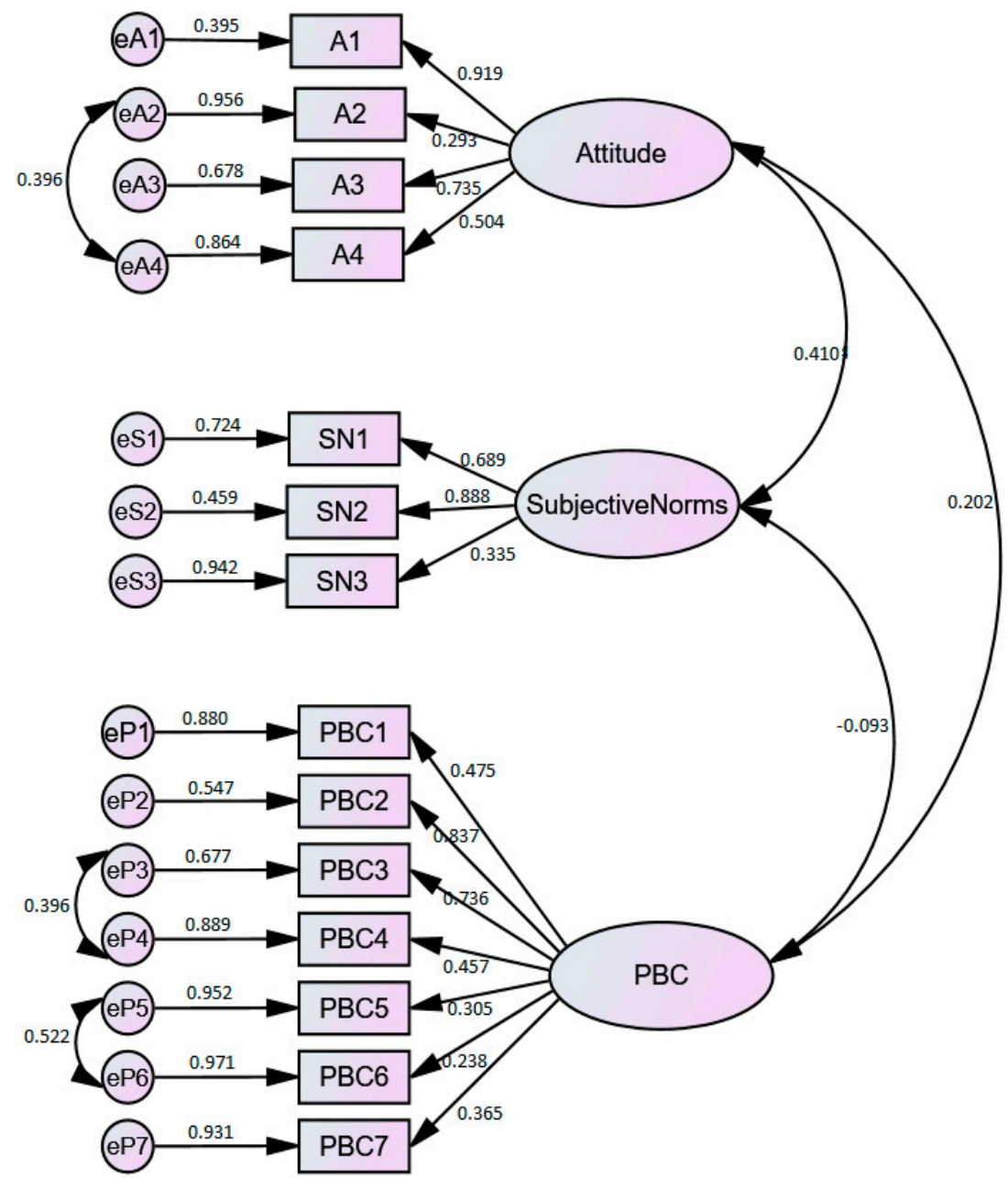

Figure 2. Three-factor CFA model results.

The inclusion of the three covariances in the model led to significantly improved model-fit statistics (corrected $\Delta$ S-B chi-square $=105.946, p<0.001)$ (e.g., see Byrne [34]), and substantially improved fit indices $(\mathrm{S}-\mathrm{B}$ chi-square $(71 \mathrm{df})=139.709$; chi-square-ratio $=1.967 ; \mathrm{NFI}=0.842 ; \mathrm{NNFI}=0.889 ; \mathrm{CFI}=0.913$; IFI $=0.915 ;$ RMSEA $=0.067$, with a $90 \%$ confidence interval from 0.05-0.083). Carmines and McIver [39] recommend a chi-square ratio below 3 as indicative of good model fit, while $\mathrm{Hu}$ and Bentler [40] provide guidelines for the interpretation of the multiple indices. 
The three covariances can be explained as follows: both the attitudinal items of 'Recycling is not worth the cost incurred by recycling companies' and 'Recycling is not worth the effort incurred by households', were phrased in the negative, while the notion of 'cost' can be seen as synonymous with 'effort'. It is, therefore, plausible for these two items to be strongly correlated. Similarly, both the PBC items of ' ... is there sufficient space or facilities in your yard to do recycling?' and '.. is there sufficient space or facilities inside your estate to do recycling?' refer to perceived levels of sufficient space for recycling outside the unit. Finally, both the PBC items of ' ... does your body corporate or resident association promote or support recycling inside your estate?' and '... do recycling companies have access to your estate to collect recyclables?' can be expected to be strongly correlated, as both forms of control were absent at the time of the study. Also, most respondents are likely to have realised that access for recycling companies would have depended on support from the body corporate. The results from the CFA suggest that the items formulated in this study to operationalize the TPB constructs of 'attitude', 'subjective norm', and 'perceived behavioural control' can be considered for further recycling studies in similar settings.

\subsection{Determinants of Household Recycling}

We subsequently examine the effect of the three constructs of 'attitude', 'subjective norm', and 'perceived behavioural control' on household recycling participation in Equestria. Moderating effects of socio-demographic variables are not included as respondents reported household and not individual recycling participation. Table 3 shows composite mean ratings across all items for each of the three constructs for both households that have recycled dry materials in the last three months at the time of the study (i.e., 'recyclers') and households that did not recycle (i.e., 'non-recyclers'), coupled with $t$-test results for group differences.

Table 3. Group differences regarding TPB constructs.

\begin{tabular}{|c|c|c|c|c|c|c|}
\hline Construct & Group & $\begin{array}{c}\text { Frequency, } \\
\text { n }\end{array}$ & $\begin{array}{c}\text { Composite } \\
\text { Mean }\end{array}$ & $\begin{array}{c}\text { Standard } \\
\text { Deviation }\end{array}$ & $t$-Statistic & $p$-Value \\
\hline \multirow{2}{*}{ Attitude } & Recyclers & 91 & 1.619 & 0.528 & \multirow{2}{*}{-1.874} & \multirow{2}{*}{0.062} \\
\hline & Non-recyclers & 199 & 1.750 & 0.596 & & \\
\hline \multirow{2}{*}{$\begin{array}{c}\text { Subjective } \\
\text { norm }\end{array}$} & Recyclers & 91 & 2.150 & 0.754 & \multirow{2}{*}{-1.954} & \multirow{2}{*}{0.052} \\
\hline & Non-recyclers & 197 & 2.354 & 0.952 & & \\
\hline \multirow{2}{*}{$P B C$} & Recyclers & 91 & 2.709 & 0.854 & \multirow{2}{*}{4.233} & \multirow{2}{*}{$0.000^{1}$} \\
\hline & Non-recyclers & 199 & 2.264 & 0.781 & & \\
\hline
\end{tabular}

${ }^{1}$ Significant at the 0.05 level (equal variances not assumed).

Table 3 shows that there were modest differences between recyclers and non-recyclers with regard to 'attitude' and 'subjective norm' $(0.05<p<0.1)$. In fact, recyclers and non-recyclers felt almost equally positive about recycling, with little variation in responses amongst recyclers and non-recyclers themselves regarding their attitude towards recycling ( $\mathrm{s}=0.528$ and 0.596 , respectively). This was supported by a review of written responses to the open-ended question at the end of the questionnaire, in which close to a third of all respondents expressed support for recycling without a single response to the contrary. Martin et al. [10] also found little difference in attitudes between recyclers and non-recyclers in Burnley (UK). Similarly, both recyclers and non-recyclers felt social pressure to recycle, although perhaps less so than what their own positive attitude may cause them to do. Previous studies also confirm that positive attitudes have a more significant effect on recycling than social norms $[18,24,41]$.

Recyclers and non-recyclers differed significantly with regard to $\mathrm{PBC}$, with non-recyclers feeling significantly less able to recycle compared to recyclers $(p<0.001)$. Written responses to the open-ended question suggested that non-recyclers did not know what or how to recycle nor did they have the necessary facilities. Ando and Gosselin [11] similarly found a strong correlation between convenience and recycling rates in multi-family dwellings in the US. Thus, the perceived ability to recycle (or lack 
thereof) appears to be the only significant factor of the three core factors in the TPB effecting household recycling in Equestria. This contradicts earlier studies in which PBC did not appear to be a significant determinant of recycling participation ([23] Boldero cited Tonglet et al. [18] (p. 198)), although these studies conceptualised storage space and access to recycling facilities as 'situational' rather than as PBC factors (e.g., see Boldero cited Tonglet et al. [18] (p. 199)).

\subsection{Spatial and Physical Proposals to Increase Household Recycling}

As stated earlier, limited space in and around townhouses (in terms of how many South Africans may perceive it), restricted access to townhouse complexes, and limited communal or intermediate space for recycling facilities inside complexes, all present possible spatial and physical obstacles to recycling in the typical South African townhouse complex. We, therefore, included five-point Likert scales that asked respondents about the extent to which four spatial and physical proposals tailored to townhouse settings may cause their households to recycle more or not, with ' 1 ' being 'not at all' and ' 5 ' being 'to a large extent'.

The proposals included:

1. Provision of facilities for recycling as part of the kitchen layout (e.g., space for additional refuse bins);

2. Provision of facilities for recycling as part of the backyard (e.g., space for containers or additional wheelie-bins);

3. Provision of a system whereby the management agency arranges access for a recycling company to collect recyclables from collection points inside the complex/estate; and

4. Provision of a system whereby the management agency arranges access for a recycling company to collect recyclables from the kerbside (sidewalk) inside the complex/estate.

Table 4 shows mean ratings for each proposal for both recyclers and non-recyclers, coupled with $t$-test results for group differences.

Table 4. Group differences regarding proposals.

\begin{tabular}{|c|c|c|c|c|c|c|}
\hline Proposal & Group & Frequency, n & Mean & Standard Deviation & $t$-Statistic & $p$-Value \\
\hline \multirow{3}{*}{$\# 1$} & Recyclers & 90 & 3.644 & 1.501 & \multirow{3}{*}{1.710} & \multirow{3}{*}{0.089} \\
\hline & Non-recyclers & 195 & 3.313 & 1.566 & & \\
\hline & Combined & 285 & 3.418 & 1.551 & & \\
\hline \multirow{3}{*}{$\# 2$} & Recyclers & 91 & 3.791 & 1.442 & \multirow{3}{*}{2.105} & \multirow{3}{*}{$0.037^{1}$} \\
\hline & Non-recyclers & 194 & 3.397 & 1.541 & & \\
\hline & Combined & 285 & 3.523 & 1.519 & & \\
\hline \multirow{3}{*}{$\# 3$} & Recyclers & 89 & 4.045 & 1.278 & \multirow{3}{*}{1.571} & \multirow{3}{*}{0.118} \\
\hline & Non-recyclers & 193 & 3.782 & 1.359 & & \\
\hline & Combined & 282 & 3.865 & 1.338 & & \\
\hline \multirow{3}{*}{$\# 4$} & Recyclers & 87 & 4.046 & 1.284 & \multirow{3}{*}{2.069} & \multirow{3}{*}{$0.040^{1}$} \\
\hline & Non-recyclers & 192 & 3.698 & 1.339 & & \\
\hline & Combined & 279 & 3.806 & 1.330 & & \\
\hline
\end{tabular}

${ }^{1}$ Significant at the .05 level (equal variances not assumed).

Each proposal is likely to cause households overall to recycle more, albeit to some extent only, considering that all of the combined mean scores fall between ' 3 ' and ' 4 ' ' on a five-point scale. However, standard deviations suggest considerable variation in responses amongst both recyclers and non-recyclers, suggesting that some households may now start to recycle, or recycle even more than they currently do, whereas others may still not recycle at all or recycle anything more than they currently do. Proposal \#3 (providing collection points for recyclables inside the complex/estate) is likely to increase recycling the most, with no statistically significant differences in ratings between recyclers and non-recyclers $(p=0.118)$. This was supported by several written responses to the 
open-ended question that residents would be willing to take recyclables to centralised collection points within their complex, provided that management properly informs them on what, when and how to recycle, and that the facilities are properly maintained. Proposal \#4 (collecting recyclables from the kerbside (sidewalk) inside the complex/estate) is second most likely to increase recycling, although there were significant differences in ratings between recyclers and non-recyclers $(p=0.040)$, with recyclers more likely to recycle even more compared to non-recyclers. Non-recyclers may not have been in favour of recyclables being left on sidewalks, or may have perceived sidewalks to be inadequate for the collection of recyclables, or may not have been in favour of recycling companies gaining unrestricted access to all parts of the complex.

Interestingly, Proposal \#1 (providing facilities for recycling as part of the kitchen layout) was rated least likely to increase recycling. We expected this proposal to lead to a stronger intention to recycle compared to the other three proposals since respondents find themselves in kitchens on a daily basis. There are perhaps three possible explanations for the latter, if not more. Respondents may have thought that kitchen layouts in townhouses are less of a problem and that recycling of dry materials can rather be served through other means. Respondents may also have thought that kitchens in townhouses cannot really accommodate additional facilities, and that they would rather take recyclables to collection points outside their units. Finally, households that may have been renting would have seen little point in altering the layout of someone else's kitchen. Further research is needed to confirm these explanations.

\section{Discussion}

Most recyclers, as well as non-recyclers, indicated that each of the four proposals tailored toward increasing recycling within townhouses may well cause them to recycle more. This corresponds with Lakhan's [13] finding that residents in multi residential buildings would be more amenable to recycling if it was made more convenient. The proposal most likely to increase recycling included the provision of collection points inside the complex. Households in Exeter (UK) and Kuala Lumpur (Malaysia) were actually more likely to recycle if they had access to a kerbside recycling scheme [29,42]. The stronger preference in Equestria for collection points rather than kerbside collection is probably due to the spatial configuration of typical townhouse complexes and a number of perceived benefits for households. Townhouse complexes are usually access controlled with small, or even no, sidewalks, which would make kerbside collection difficult. Collection points circumvent this problem and may offer other benefits. For example, households can drop recyclables at strategically located collection points that are both accessible for recycling companies and within walking distance from their units, thereby reducing the need to store recycles in kitchens or backyards. Moreover, restricting recycling companies to collection points between townhouse complexes rather than within complexes is likely to make them less of a nuisance or a security threat, and sidewalks are then also kept clean of recyclables. Collection points are also likely to be more cost effective for recycling companies, since collection distances would be reduced. Figure 1 shows that the tree-like layout of Equestria would make kerbside collection costly for companies and difficult to gain access to individual townhouse complexes. Planners and architects can easily provide strategically located collection points for recyclables by slightly altering the way they currently plan and design townhouse complexes.

Yet, spatial and physical proposals (i.e., 'convenience' factors) are by themselves not enough to increase recycling in townhouses to more sustainable levels. Lakhan [13], for example, found that the installation of recycling chutes in multi-residential buildings did not result in a significant increase in recycling, even though residents asked for recycling to be made more convenient (see also Nguyen et al. [43]). Much also depends on how well recycling is managed as part of the day-to-day operation of sectional title schemes, and how well households from diverse backgrounds are informed and encouraged to recycle [16,44-47]. More specifically, the mere provision of strategically located collection points, even though it was found to be the most preferred option for households in this study, is also by itself not enough to sustain recycling in townhouses. The manner in which collection 
points are located and designed should maximise the accessibility and visibility thereof. Lakhan [13] and Thomas and Sharp [1] suggest that the normative nature of recycling requires it to be visible to non-recyclers, so that recycling becomes an established practice in a community.

Unfortunately, the practice of providing mono-functional townhouse developments with little or no communal or intermediary spaces to accommodate recycling facilities still prevails in South Africa. Settlement planning and design guidelines should include tangible specifications for the provision of recycling facilities across different housing types that are simultaneously linked to economic instruments (EIs) as part of waste policy and legislation [4]. Though it may be assumed that recycling will necessarily increase if it is made easier, careful planning and design of settlements and housing, coupled with proper management and incentives for recycling, is actually necessary to sustain increased levels of recycling. This study highlighted that the provision of preferred recycling facilities does not necessarily require a major change in the current design of housing and residential complexes, just that the provision of facilities should be appropriate for the specific housing type and community concerned.

\section{Conclusions}

This article examined factors affecting household recycling in townhouse complexes in Equestria, an enclosed middle-income residential estate in Pretoria, South Africa. With a substantive body of research on the relative effects of attitudinal and normative factors, but less so on control factors, we were particularly interested in the effects of spatial and physical factors on recycling considering the enclosed and medium-density nature of townhouse complexes-a housing type that has expanded noticeably in South Africa. Using the Theory of Planned Behaviour, we examined the relative effect of 'attitude', 'subjective norm', and 'perceived behavioural control'. A confirmatory factor analysis verified the construct validity of these three factors. Despite low levels of household recycling in South Africa, both recyclers and non-recyclers showed positive attitudes toward recycling and felt social pressure to recycle. With no formal recycling facilities in place at the time of the study, non-recyclers felt significantly less able to recycle, while both recyclers and non-recyclers evaluated a number of spatial and physical proposals that may cause them to recycle more.

South Africa's recycling and medium-density housing policies will be in conflict if both sets of policies do not address recycling behaviour in medium-density housing such as townhouses. Minor changes in the current planning and design of townhouse complexes to help facilitate recycling, coupled with well-managed recycling facilities and a culture of recycling amongst residents that is accommodative of socio-demographic diversity can, therefore, noticeably increase household recycling in South Africa and other developing countries with similar housing types. Although it is widely accepted that to establish recycling as a norm requires well-targeted and integrated approaches addressing attitudinal, normative and control factors, further research on how to successfully facilitate recycling in enclosed medium-density housing is still necessary, both in South Africa and other developing countries. This study, being arguably the first to examine the applicability of the Theory of Planned Behaviour in examining recycling behaviour in townhouses, highlighted the importance of control factors in town houses, and provides a basis for further studies that may include additional independent constructs such as moral norm, past experience, situational factors, and perceived consequences of recycling.

Supplementary Materials: Supplementary Materials are available online at www.mdpi.com/2071-1050/9/11/ $2033 /$ s1.

Acknowledgments: The following students served as fieldworkers for this research whilst they were final year students in Town and Regional Planning at the University of Pretoria: Jean-Pierre Adendorff, Heidri Bindemann-Nel, Kailash Chetty, Ryno Coetzer, Johan Herbst, Dineo Lesejane, and Zamanhlenga Mpanza. 
Author Contributions: Jacques du Toit conceived, designed and led the study, and served as first author; Claire Wagner conducted parts of the literature review and served as second co-author; and Lizelle Fletcher conducted the confirmatory factor analysis and served as third co-author.

Conflicts of Interest: The authors declare no conflict of interest.

\section{References}

1. Thomas, C.; Sharp, V. Understanding the normalisation of recycling behaviour and its implications for other pro-environmental behaviours: A review of social norms and recycling. Resour. Conserv. Recycl. 2013, 79, 11-20. [CrossRef]

2. Simatele, D.M.; Dlamini, S.; Kubanza, N.S. From informality to formality: Perspectives on the challenges of integrating solid waste management into the urban development and planning policy in Johannesburg, South Africa. Habitat Int. 2017, 63, 122-130. [CrossRef]

3. Department of Environmental Affairs and Tourism (DEAT). National Waste Information Baseline Report. 2012. Available online: http:/ / www.sawic.environment.gov.za/documents/1880.pdf (accessed on 7 April 2017).

4. Nahman, A.; Godfrey, L. Economic instruments for solid waste management in South Africa: Opportunities and constraints. Resour. Conserv. Recycl. 2010, 54, 521-531. [CrossRef]

5. Mbiba, B. Urban solid waste characteristics and household appetite for separation at source in Eastern and Southern Africa. Habitat Int. 2014, 43, 152-162. [CrossRef]

6. Oelofse, S. All South African Households in Large Centres to Separate Household Waste by 2016. 2012. Available online: http:/ / www.csir.co.za/enews/2012_nov/01.html (accessed on 7 April 2017).

7. Oelofse, S.H.H.; Strydom, W.F. The trigger to recycling in a developing country-In the absence of command-and-control instruments. In Proceedings of the Waste 2010: Waste and Resource Management-Putting Strategy into Practice Stratford-upon-Avon, Warwickshire, UK, 28-29 September 2010; pp. 355-364.

8. Tonkin, A. Sustainable Medium-Density Housing: A Resource Book; Development Action Group: Cape Town, South Africa, 2008.

9. Department of Human Settlements (DHS). Sustainable Human Settlements: Investment Potential-Atlas 2009; National Department of Human Settlements: Pretoria, South Africa, 2009.

10. Martin, M.; Williams, I.; Clark, M. Social, cultural and structural influences on household waste recycling: A case study. Resour. Conserv. Recycl. 2006, 48, 357-395. [CrossRef]

11. Ando, A.W.; Gosselin, A.Y. Recycling in multi-family dwellings: Does convenience matter? Econ. Enq. 2005, 43, 426-438. [CrossRef]

12. Schwebel, M.B. How can a successful multi-family residential recycling programme be initiated within Baltimore City, Maryland? Waste Manag. Res. 2012, 30, 727-737. [CrossRef] [PubMed]

13. Lakhan, C. Out of sight, out of mind: Issues and obstacles to recycling in Ontario's multi residential buildings. Resour. Conserv. Recycl. 2016, 108, 1-9. [CrossRef]

14. Timlett, R.E.; Williams, I.D. The impact of transient populations on recycling behaviour in a densely populated urban environment. Resour. Conserv. Recycl. 2009, 53, 498-506. [CrossRef]

15. Siu, K.W.M.; Xiao, J.X. Quality of life and recycling behaviour in high-rise buildings: A case in Hong Kong. Appl. Res. Qual. Life 2016, 11, 1137-1154. [CrossRef]

16. Zen, I.S.; Noor, Z.Z.; Yusuf, R.O. The profiles of household solid waste recyclers and non-recyclers in Kuala Lumpur, Malaysia. Habitat Int. 2014, 42, 83-89. [CrossRef]

17. Ajzen, I. From intentions to action: A theory of planned behaviour. In Action Control: From Cognition to Behaviors; Kuhl, J., Beckman, J., Eds.; Springer: New York, NY, USA, 1985; pp. 11-39.

18. Tonglet, M.; Phillips, P.S.; Read, A.D. Using the Theory of Planned Behaviour to investigate the determinants of recycling behaviour: A case study from Brixworth, UK. Resour. Conserv. Recycl. 2004, 41, 191-214. [CrossRef]

19. Botetzagias, I.; Dima, A.-F.; Malesios, C. Extending the Theory of Planned Behavior in the context of recycling: The role of moral norms and of demographic predictors. Resour. Conserv. Recycl. 2015, 95, 58-67. [CrossRef]

20. Nduneseokwu, C.K.; Qu, Y.; Appolloni, A. Factors influencing consumers' intention to participate in a formal e-waste collection system: A case study of Onitsha, Nigeria. Sustainability 2017, 9, 881. [CrossRef] 
21. Xu, L.; Ling, M.; Lu, Y.; Shen, M. Understanding household waste separation behaviour: Testing the roles of moral, past experience, and perceived policy effectiveness within the Theory of Planned behaviour. Sustainability 2017, 9, 625. [CrossRef]

22. Ajzen, I. Constructing a TPB Questionnaire: Conceptual and Methodological Considerations. 2013. Available online: http:/ / people.umass.edu/aizen/pdf/tpb.measurement.pdf (accessed on 7 April 2017).

23. Davies, J.; Foxall, G.R.; Pallister, J. Beyond the intention-behaviour mythology: An integrated model of recycling. Mark. Theory 2002, 2, 29-113. [CrossRef]

24. Knussen, C.; Yule, F.; MacKenzie, J.; Wells, M. An analysis of intentions to recycle household waste: The roles of past behaviour, perceived habit, and perceived lack of facilities. J. Environ. Psychol. 2004, 24, 237-246. [CrossRef]

25. Chen, M.-F.; Tung, P.-J. The moderating effect of perceived lack of facilities on consumers' recycling intention. Environ. Behav. 2010, 42, 824-844. [CrossRef]

26. Derksen, L.; Gartrell, J. The social context of recycling. Am. Sociol. Rev. 1993, 58, 434-442. [CrossRef]

27. Stern, P.C. Toward a coherent theory of environmentally significant behavior. J. Soc. Issues 2000, 56, 407-424. [CrossRef]

28. Swami, V.; Chamorro-Premuzic, T.; Snelgar, R.; Furnham, A. Personality, individual differences, and demographic antecedents of self-reported household waste management behaviours. J. Environ. Psychol. 2011, 31, 21-26. [CrossRef]

29. Zen, I.S.; Siwar, C. An analysis of household acceptance of curbside recycling scheme in Kuala Lumpur, Malaysia. Habitat Int. 2015, 47, 248-255. [CrossRef]

30. Barr, S. Factors influencing environmental attitudes and behaviours. A UK case study of household waste management. J. Environ. Behav. 2007, 39, 435-473. [CrossRef]

31. Thøgersen, J. A model of recycling behaviour, with evidence from Danish source separation programmes. Int. J. Res. Mark. 1994, 11, 145-163. [CrossRef]

32. Kline, R.B. Principles and Practice of Structural Equation Modelling, 2nd ed.; The Guildford Press: New York, NY, USA, 2005.

33. Wan, C.; Shen, G.Q.; Choi, S. Experiential and instrumental attitudes: Interaction effect of attitude and subjective norm on recycling intention. J. Environ. Psychol. 2017, 50, 69-79. [CrossRef]

34. Byrne, B.M. Structural Equation Modeling with EQS, 2nd ed.; Lawrence Erlbaum Associates, Inc.: Mahwah, NJ, USA, 2006.

35. Marsh, H.W.; Balla, J.R.; McDonals, R.P. Goodness-of-fit indices in confirmatory factor analysis. Psychol. Bull. 1988, 103, 391-410. [CrossRef]

36. Chou, C.; Bentler, P.M. Model modification in covariance structure modeling behaviour: A comparison among likelihood ratio, Lagrange multiplier and Wald tests. Multivar. Behav. Res. 1990, 25, 115-136. [CrossRef] [PubMed]

37. Barr, S.; Gilg, A.W.; Ford, N.J. Differences between household waste reduction, reuse and recycling behaviour: A study of reported behaviours, intentions and explanatory variables. Environ. Waste Manag. 2001, 4, 69-82.

38. Huffman, A.H.; Van der Werff, B.R.; Henning, J.B.; Watrous-Rodriguez, K. When do recycling attitudes predict recycling? An investigation of self-reported versus observed behavior. J. Environ. Psychol. 2014, 38, 262-270. [CrossRef]

39. Carmines, E.; McIver, J. Analysing models with unobserved variables: Analysis of covariance structures. In Social Measurement; Bohrnstedt, G., Borgatta, E., Eds.; Sage: Beverley Hills, CA, USA, 1981; pp. 65-115.

40. Hu, L.; Bentler, P.M. Cut-off criteria for fit indexes in covariance structure analysis: Conventional criteria versus new alternatives. Struct. Equ. Model. 1999, 6, 1-55. [CrossRef]

41. White, K.M.; Smith, J.R.; Terry, D.J.; Greenslade, J.H.; McKimmie, B.M. Social influence in the theory of planned behaviour: The role of descriptive, injunctive and in-group norms. Br. J. Soc. Psychol. 2009, 48, 135-158. [CrossRef] [PubMed]

42. Barr, S.; Ford, N.J.; Gilg, A.W. Attitudes towards recycling household waste in Exeter, Devon: Quantitative and qualitative approaches. Local Environ. 2003, 8, 407-421. [CrossRef]

43. Nguyen, T.N.; Nguyen, H.V.; Lobo, A.; Dao, T.S. Encouraging Vietnamese household recycling behaviour: Insights and implications. Sustainability 2017, 9, 179. [CrossRef] 
44. Kamara, A. Household Participation in Domestic Waste Disposal; Recycling in the Tshwane Metropolitan Area: An Environmental Education Perspective. Master's Thesis, University of South Africa, Pretoria, South Africa, June 2006.

45. Anderson, B.; Romani, J.; Wentzel, M.; Phillips, H. Recycling Behaviour among Urban South Africans: The Role of Race and Social Status. 2013. Available online: http://www.psc.isr.umich.edu/pubs/abs/8920 (accessed on 7 April 2017).

46. Nguyen, T.T.P.; Zhu, D.; Le, N.P. Factors influencing waste separation intention of residential households in a developing country: Evidence from Hanoi, Vietnam. Habitat Int. 2014, 48, 169-176. [CrossRef]

47. Oyekale, A.S. Factors explaining households' cash payment for solid waste disposal and recycling behaviors in South Africa. Sustainability 2015, 7, 15882-15899. [CrossRef]

2017 by the authors. Licensee MDPI, Basel, Switzerland. This article is an open access article distributed under the terms and conditions of the Creative Commons Attribution (CC BY) license (http:/ / creativecommons.org/licenses/by/4.0/). 